\title{
Avatares de la lucha obrera en la época neoliberal: la experiencia de la Sociedad Cooperativa Trabajadores Democráticos de Occidente
}

\author{
Avatars of the workers' struggle in the neoliberal \\ era:The experience of the Cooperative Society \\ Democratic Workers of the West
}

Juan José Rojas Herrera•

\begin{abstract}
Resumen
En este documento se expone, en términos generales, el proceso de desarrollo de la Sociedad Cooperativa Trabajadores Democráticos de Occidente, desde sus orígenes en el Sindicato Único Revolucionario de Trabajadores de Euzkadi a principios de los años treinta, hasta la actualidad, a fin de destacar la forma en que ha sorteado los retos que el contexto económico y político del país le ha planteado en distintos momentos de su devenir histórico. Se trata de una experiencia que vale la pena relatar porque está llena de matices, de avances y retrocesos que obligan a un constante cambio de estrategias como las que supone pasar de una organización sindical a otra cooperativa y finalmente a manejar ambas formas de participación social, sin perder de vista que lo determinante, en última instancia, es lograr la apropiación directa del valor generado en el proceso productivo.
\end{abstract}

Palabras clave: cooperativismo, autogestión, sindicalismo, industria automotriz, Estado.

\begin{abstract}
This document sets out, in general terms, the process of development of the Cooperative Society of Democratic Workers of the West, from its origins in the Unique Revolutionary Union of Euzkadi Workers at the beginning of the 1930 decade, to the present, in order to highlight the way in which that organism has overcome the challenges that the economic and political context of the country has raised at different times of its historical evolution. It is an experience worth telling because it is full of nuances, of advances and setbacks that force a constant change of strategies such as those that it means moving from one union organization to another cooperative, and finally managing both forms of social participation without losing sight of that the most important, ultimately, is to achieve the direct appropriation of the value generated in the productive process.
\end{abstract}

Keywords: cooperativism, self-management, trade unionism, automotive industry, State.

\footnotetext{
- Doctor en Ciencias Económicas y Empresariales por la Universidad de Córdoba, España. Profesor-investigador en el Departamento de Sociología Rural de la Universidad Autónoma Chapingo. Líneas de investigación: cooperativismo, economía solidaria y movimientos sociales en el campo.r rojashij@ gmail.com. Orcid: 0000-0002-9758-7463.

Fecha de recepción: 7 de febrero de 2020. Fecha de aceptación: 21 de enero de 2021.
} 


\section{Introducción}

El 5 de diciembre de 2019, la Sociedad Cooperativa Trabajadores Democráticos de Occidente (Tradoc) cumplió 15 años de fundada y la celebración de este aniversario, como se verá más adelante, se dio en medio de un brusco e imprevisto vuelco en su desarrollo como organización autónoma e independiente. Nacida en diciembre de 2004 como producto de una cruenta huelga al interior de la Compañía Hulera Euzkadi, propiedad del consorcio transnacional Continental, luego de poco más de tres años de lucha el $50 \%$ de la planta industrial fue entregada a 587 trabajadores, como pago de sus salarios caídos. La otra mitad fue adquirida por la empresa queretana Llanti Systems. Actualmente cuenta con 580 asociados y es una de las mayores cooperativas de trabajadores de México dedicada a la producción de llantas.

A lo largo de su aún corta vida, Tradoc se ha convertido en un importante referente de la lucha por la dignidad de los trabajadores y en contra de los sistemas de explotación del capital. Entre sus logros más destacados se encuentran las mejoras alcanzadas en las condiciones de vida de los socios y sus familias, merced a la atención brindada en diversos aspectos como salud, educación, vivienda y recreación. Pero quizás lo más significativo de esta experiencia es que los beneficios no sólo se han quedado en sus instalaciones, sino que han tenido efectos positivos en el desarrollo local de los municipios de El Salto y Juanacatlán, donde residen la mayoría de sus asociados. ${ }^{1}$

I. De acuerdo con datos del Instituto de Información Estadística y Geográfica de Jalisco (2019 a y b), los municipios de El Salto y Juanacatlán forman parte de la región centro del estado. Hacia 2015, el primero de ellos, con una extensión de 92 kilómetros cuadrados, tenía una población de 183,437 habitantes.Juanacatlán, por su parte, en una superficie de $14 \mathrm{I}$ kilómetros cuadrados albergaba una población de 17,955 personas. Lamentablemente en esta región los recursos hidrológicos sufren una cada vez más peligrosa contaminación (Martínez y Hernández, 2009). 
Avatares de a lucha obrera en la época neoliberal: la experiencia de la Sociedad Cooperativa Trabajadores Democráticos de Occidente

En este orden de ideas, el propósito general de este documento consiste en exponer, en grandes rasgos, el proceso de desarrollo histórico de la cooperativa Tradoc, desde sus orígenes en el Sindicato Único Revolucionario de Trabajadores de Euzkadi (SURTE) hasta la actualidad, a fin de destacar la forma en que ha sorteado los retos que el contexto económico y político del país le ha planteado en distintos momentos de su devenir histórico.

En correspondencia con lo anterior, la metodología empleada en el presente estudio es de corte cualitativo y está enfocada en la recuperación y sistematización de experiencias con la finalidad de lograr una correcta objetivación del fenómeno estudiado que, como señala Oscar Jara (2018: 76), permita observarlo desde lejos y con una visión de conjunto, de tal modo que sea posible "comprender e interpretar las razones y sentidos de fondo para que esos procesos se dieran de esa manera; la relación que se dio entre sus múltiples factores; las consecuencias y sus causas; las contradicciones, coherencias e incoherencias; continuidades y rupturas; vínculos y ausencias [...]”, inherentes a la experiencia organizativa de la cooperativa Tradoc.

Las fuentes de información utilizadas consistieron, por una parte, en revisión de material bibliográfico y hemerográfico, así como de documentos básicos de la cooperativa: bases constitutivas, reglamentos, informes anuales del consejo de administración, actas de asamblea general, etc. Por otra parte, se aplicó la observación participante de los procesos productivos y de toma de decisiones y se realizaron diversas entrevistas en profundidad, tanto con integrantes de los órganos directivos como con socios de base.

Desde el punto de vista teórico, cabe destacar que el análisis e interpretación de la experiencia de mérito se realiza básicamente desde la perspectiva del paradigma emergente de la llamada economía social y solidaria, el cual se propone reflexionar acerca de las distintas modalidades 
de organización social y económica, impulsadas por una heterogeneidad de actores excluidos de relaciones laborales formales, para quienes su fuerza y valor económico radica en su propio trabajo, ejercido con criterios sociales a través de relaciones solidarias, igualitarias y equitativas de producción. Bajo este tenor, las cooperativas de productores constituyen una forma de organización privilegiada para ponderar el potencial del trabajo autogestivo como un medio de liberación humana y como una alternativa al carácter subordinado, alienante y asalariado del sistema de trabajo capitalista.

A tal efecto, la exposición se ha ordenado en cinco apartados. Los primeros cuatro dedicados al análisis de cada una de las etapas en que se ha subdividido la evolución histórica de la cooperativa, y el quinto y último destinado a presentar las conclusiones generales derivadas del presente estudio.

\section{Desarrollo histórico del Sindicato Único Revolucionario de Trabajadores de Euzkadi}

La Compañía Hulera Euzkadi, según afirma Luna (2010), fue fundada por el vasco Ángel Urraza a principios de la década de los años treinta, en la región central del país con el objeto de producir alpargatas y suelas de hule. En forma casi simultánea, en 1931 se produce el primer intento por sindicalizar a los obreros mediante la creación de la Unión Sindical de Trabajadores de Euzkadi, que cuatro años después, a través de diversas fusiones y alianzas, dio paso a la fundación del sURTE, constituido formalmente el 21 de julio de 1935 .

La formación del surTe, como señala Miranda (2016), se produjo en medio de un contexto de efervescencia de la lucha obrera a nivel nacional, que se expresaba en movilizaciones constantes, estallido de huelgas y formación de numerosos sindicatos. En el caso específico del sURTE, la labor de 
Avatares de a lucha obrera en la época neoliberal: la experiencia de la Sociedad Cooperativa Trabajadores Democráticos de Occidente

organización sindical realizada por núcleos "comunistas", identificados como "los rojos", resultó decisiva.

Al poco tiempo de creado, el sURTE participó activamente en la fundación de la Central de Trabajadores de México (CTM), ocurrida el 24 de febrero de $1936 .{ }^{2}$ Dos años después, gracias a la conformación de la Coalición de Sindicatos de la Industria Hulera y a la realización de una huelga de tres días, obtuvo una importante conquista laboral que se tradujo en la habilitación de un Contrato Ley, es decir, un sistema de contratación colectiva que se aplicaría a nivel de toda la industria hulera nacional y que incluiría, entre otros aspectos, la jornada laboral de 40 horas y 42 días de aguinaldo.

Durante las décadas de los años cuarenta y cincuenta el funcionamiento del sindicato se vio maniatado por la constante intromisión de los líderes nacionales de la СтM, particularmente de Jesús Yurén, quien en 1938 se convertiría en secretario general y lograría mantener una fuerte influencia a lo largo de 20 años, misma que concluyó de manera abrupta. En efecto, como indica Gómez (2010), en 1958, ante la fuerte contracción económica que vivía el país, la CTM lanzó la política de huelga general por un aumento salarial de emergencia del $25 \%$, aunque poco después se retractó. No obstante, el 22 de noviembre el sURTE la estalló. Inmediatamente la huelga fue declarada inexistente,

2. Si bien la formación de la СтM se dio originalmente sobre la base de organizaciones independientes pertenecientes al Comité Nacional de Defensa Proletaria (CNDP), al poco tiempo, como señala Edelmiro Maldonado (1979: 124), incentivados por el Gobierno federal, "a la nueva Confederación ingresaron poderosos sindicatos nacionales de industria como ferrocarrileros, mineros, electricistas, de artes gráficas, etc., así como numerosos sindicatos de empresa" que, poco a poco, desplazaron no sólo a los agrupamientos del cndp sino a los grupos adheridos a la corriente reformista de Vicente Lombardo Toledano. A partir de 194I, bajo la batuta de Fidel Velázquez, se apoderaron de la Dirección de la Confederación y pusieron en práctica el llamado "charrismo sindical", es decir, una estrategia de colaboración política con el Gobierno, de contención y mediatización de las luchas obreras y de control antidemocrático de las estructuras organizativas de la propia СTM. 
pero las autoridades laborales no lograron convencer a los obreros de que volvieran al trabajo. En estas condiciones, durante una asamblea general celebrada el 3 de enero de 1959, sin previo aviso y en forma altanera y provocadora, Jesús Yurén y Fidel Velázquez pidieron que dejaran las negociaciones en sus manos. Dicha propuesta enardeció a los obreros, quienes no sólo exigieron la expulsión de los líderes cetemistas de la asamblea, sino que acordaron la salida inmediata del suRTE de la CTM.

Días después, la huelga de Euzkadi se levantó con casi todas las demandas aceptadas por los empresarios. Sin embargo, "cuando estaban por firmarse los acuerdos, los trabajadores se encontraron con la planta rodeada por granaderos y con sus dirigentes sindicales despedidos. Además, se enteraron de que sus nuevos líderes sindicales (nombrados por la CTM) eran Manuel Aldana y Ángel Ortega [...]" (Gómez, 2010: 58).

No obstante lo anterior, a lo largo de los años sesenta, según señala Luna (2010: 2), a pesar de que el Comité Ejecutivo del sindicato se mantuvo copado por líderes vinculados a la CTM, el sURTE fue adquiriendo una forma de funcionamiento cada vez más democrática, ello debido a que "la corriente roja, estableció a la asamblea general como la máxima autoridad y órgano de toma de decisiones, la cual se conservó aún con otras corrientes en la dirigencia [...]". A este mismo resultado contribuyó la participación y presión constante de las bases sindicales hacia sus cuerpos directivos.

Paralelamente a los hechos antes relatados, la industria automotriz experimentó un crecimiento constante a nivel nacional, proceso que fue incentivado por el Gobierno mexicano mediante diversas acciones, entre las que destaca la emisión de dos decretos sobre esta industria, en los que se disponía que la instalación de nuevas plantas automotrices debía contemplar un porcentaje mínimo de insumos de 
Avatares de a lucha obrera en la época neoliberal: la experiencia de la Sociedad Cooperativa Trabajadores Democráticos de Occidente

contenido nacional para la fabricación de vehículos, entre los que, obviamente, se encontraban las llantas.

La expansión de la industria automotriz impacta positivamente en la empresa Euzkadi, la cual en el transcurso de la década de los sesenta instala sus plantas número 2 y 3 en el Estado de México, y en 1970 logra la apertura de la planta número 4 de El Salto, Jalisco. Este último hecho vino acompañado de la incorporación de nuevos trabajadores, a quienes la empresa pretendía concentrar en un nuevo sindicato, adherido a la CTM. Afortunadamente, como explica Ruiz (1997: 32), "los trabajadores presionaron y la empresa dio marcha atrás, pero a condición de que las plantas 1 y 3 aceptaran la introducción de la ingeniería de tiempos y movimientos sin contar con una nueva retabulación". Así pues, los trabajadores terminan aceptando las nuevas condiciones de trabajo claramente desventajosas para ellos, pero lo hacen como una medida política tendente a deshacerse definitivamente de la influencia nefasta de la стм; incluso, para hacer más evidente el distanciamiento, el sURTE cambia de nombre y se transforma en Sindicato Nacional Revolucionario de Trabajadores de Euzkadi (SNRTE).

A lo largo de la década de los setenta la planta de Euzkadi en El Salto se mantuvo como la más moderna en su género en América Latina, pero no ocurría lo mismo con el resto de las plantas, las cuales se intentó desaparecer con el consabido despido masivo de trabajadores. A cambio del cierre y despido, la única opción que la empresa ofrecía era la aceptación por parte de éstos de diversos convenios de incremento de productividad, cuya implementación, como se verá más adelante, daría lugar a diversas confrontaciones obrero-patronales.

En 1989 la empresa pasa a propiedad del Grupo Carso del magnate mexicano Carlos Slim y con ello se ejecutan tres medidas: la primera en 1992, mediante la imposición de un convenio de productividad; la segunda, en 1993, que 
se traduce en el cierre de la planta número 1, y la tercera, en el transcurso de los años noventa y que consistió en la realización de fuertes inversiones en maquinaria con tecnología de punta, que le permiten experimentar su mayor tiempo de prosperidad (Quintero, 2014).

De esta manera, muy pronto el Grupo Carso llegó a controlar el $40 \%$ de la producción de llantas en México; sin embargo, en diciembre de 1998 transfirió una parte de sus acciones a la empresa Continental, lo cual incluía la venta de Euzkadi y de General Tire de México, instalada en San Luis Potosí. La aparentemente inexplicable venta de Euzkadi, según Gómez (2010: 24), se dio “[...] a cambio de mantener el $19.4 \%$ de las acciones y 18.9 millones de dólares". Además, "la transacción incluyó que el magnate conservara un asiento en el Consejo de Administración y otro en el Comité Ejecutivo de Continental Tire de México".

Poco después, cuando la Continental Tire llega a El Salto, intenta evadir los derechos consagrados en el contrato colectivo de trabajo e imponer un agresivo programa de incremento en la productividad, que incluía la prolongación de la jornada laboral de ocho a 12 horas diarias, bajo el esquema $4 \times 3$, esto es, cuatro jornadas de 12 horas, por tres días de asueto; la reducción de personal, la eliminación del domingo como día de descanso, el traslape obligatorio, el no pago por parte de la empresa de los impuestos y cuotas del Seguro Social y un nuevo reglamento de trabajo (Cockcroft, Nájera y Torres, 2008).

En junio de 1999, con el fin de amedrentar a los trabajadores y obligarlos a aceptar las nuevas condiciones laborales, la empresa despidió a un grupo de 18 de ellos, entre éstos a Jesús Torres Nuño, quien poco después se convertiría en uno de los líderes que encabezaría la lucha contra el plan de reestructuración y, posteriormente, en 2001 en secretario general del SNRTE. En ese momento la planta de Euzkadi 
contaba con 1,164 trabajadores, 971 de ellos sindicalizados en el SNRTE (Barajas et al., 2002).

A lo largo de los difíciles años de 2000 y 2001, pese al constante golpeteo de la empresa, el SNRTE mantiene una firme disposición a negociar, aceptando incluso la realización de dos paros técnicos, los cuales tuvieron lugar en la última semana de septiembre y la segunda de octubre, de 2001. Al concluir el segundo paro, la postura de Continental para evitar el cierre de la planta industrial y lograr alcanzar un $35 \%$ de productividad, era: "despido de 200 trabajadores, o parar la fábrica durante cuatro semanas (con el 50\% del salario)" (Luna Broda, 2010: 3). La negativa del SNRTE a aceptar las condiciones que quería imponer la patronal, trajo como consecuencia que el 16 de diciembre de 2001 la empresa decidiera unilateralmente cerrar la fábrica de El Salto, Jalisco, despidiendo a todos sus trabajadores.

Los cruentos años de la huelga: 2002-2005

Tres días después del arbitrario cierre de la planta industrial, decretado por la compañía alemana Continental, sin apegarse a lo dispuesto en los artículo 434 y 435 de la Ley Federal del Trabajo en los que se dispone que el cierre de una empresa únicamente puede realizarse por incosteabilidad notoria, agotamiento de materia de trabajo, concurso o quiebra y por incapacidad física o mental del patrón, lo cual debe acreditarse mediante trámite ante la Junta de Conciliación y Arbitraje correspondiente, los obreros se reunieron en asamblea general, al cabo de la cual decidieron impulsar la lucha legal para exigir la reapertura. Ese mismo día, 19 de diciembre de 2001, la empresa depositó las liquidaciones correspondientes en las mesas 17 y 18 de la Junta Federal de Conciliación y Arbitraje (JFCA) y, junto con lo anterior, en un acto claramente intimidatorio con- 
trató mercenarios, al parecer ex marines, para resguardar la planta (Monterrubio, 2012).

Durante las últimas dos semanas de diciembre de 2001 y los primeros días de enero de 2002, los trabajadores, además de resguardar las instalaciones fabriles, interpusieron un total de 913 demandas individuales por reinstalación. De esta manera lograron impedir que la empresa sacara la maquinaria y equipo instalados, al tiempo que se mantuvieron en espera de que se acumularan mayores violaciones a su contrato de Ley y pudieran, legalmente, estallar en huelga.

Esto último ocurrió el 22 de enero, cuando al no pagar los salarios correspondientes a las semanas transcurridas de ese mes, la empresa incurrió en violación flagrante del contrato laboral vigente. Empero, la huelga sólo sería reconocida dos años después, es decir, hasta el 23 de enero de 2004. Antes de ello, el 22 de marzo de 2002, sin haber realizado una audiencia de calificación, la JFCA declaró improcedente la huelga. Tiempo después

[...] la Suprema Corte de Justicia de la Nación (scjn) determinó que la calificación de "improcedencia" no figuraba en la Ley Federal del Trabajo [...], lo cual le dio un nuevo respiro al movimiento [...] y la autoridad moral y jurídica para reclamar la reapertura incondicional de la planta de Euzkadi (Atilano Uriarte, 2017: 28).

Dada esta circunstancia, los obreros resuelven concentrar sus esfuerzos en el ámbito de la resistencia y la movilización política.

Bajo esta orientación, la primera movilización de ámbito nacional tuvo lugar del 31 de enero al 5 de febrero de 2002, período durante el cual recorren los estados de Aguascalientes, San Luis Potosí, Guanajuato, Hidalgo, Puebla, Estado de México y Distrito Federal. El recorrido de la caravana obrera, integrada por cerca de 300 trabajadores a bordo de 10 autobuses, culmina en la Ciudad de México con una 
Avatares de a lucha obrera en la época neoliberal: la experiencia de la Sociedad Cooperativa Trabajadores Democráticos de Occidente

marcha del Ángel de la Independencia al Zócalo, logrando reunir a más de 10,000 personas (Gómez, 2010).

A partir de mayo de 2002 se inicia la lucha en el ámbito internacional, cuyos pormenores derivados de las entrevistas realizadas a Enrique Gómez Delgado y Jesús Torres Nuño, así como los elementos recuperados de diversos materiales escritos, puede relatarse sintéticamente en los términos que a continuación se apuntan. Por acuerdo de la Asamblea General del sindicato, se forma una comisión integrada por el secretario general del SNRTE, Jesús Torres Nuño; el asesor político del movimiento, Enrique Gómez Delgado, y el consejero jurídico del sindicato, Oscar Rubio González. El mandato otorgado por la asamblea a esta comisión consiste en trasladarse al viejo continente con el propósito de exponer su problema ante la asamblea de accionistas de la Continental Tire y lograr una resolución favorable a sus demandas. Con esta idea, recorren España, Francia y Alemania. En París reciben la solidaridad del Sindicato de Michelin y de los eurodiputados de la fracción de la Liga Comunista Revolucionaria de Francia; viajan a la sede del Parlamento Europeo en Estrasburgo, donde exponen detalles del conflicto y mediante la intervención de los eurodiputados Alain Krivine y Roselyne Bachette, les permiten distribuir propaganda impresa (Monterrubio, 2012).

En Madrid son invitados a participar en el Foro Social Trasatlántico, en donde exponen diversos aspectos de su lucha. Realizan, además, largas entrevistas con representantes de las Comisiones Obreras y de la Central General de Trabajadores de España. En Barcelona reciben el apoyo de los sindicatos de Pirelli y seat; en Vitoria, País Vasco, visitan al comité de empresa de Michelin, el cual ofrece respaldar su lucha (Gómez, 2010).

Pero, conforme a lo previsto, el arribo a Berlín el 28 de mayo de 2002, a tan sólo 264 kilómetros de Hannover, sede de Continental Tire, se convertiría en el punto nodal del 
apoyo político a su causa. En esa ciudad consiguen el respaldo de cinco importantes organizaciones sociales, a saber: la Asociación para la Tasación de las Transacciones Financieras y de Ayuda a los Ciudadanos (ATTAC), constituida para oponerse a los excesos del capitalismo global; la Iniciativa Norte-Sur de German Watch, organización defensora de los derechos humanos; la Red de Acción e Información: $L a$ Alimentación es Primero (FIAN por sus siglas en inglés), formada en 1986 con el objetivo de luchar por el derecho a una alimentación saludable; la Coordinadora Alemana por el Internacionalismo (BURKo), consagrada a brindar solidaridad activa a las luchas de los pueblos del llamado tercer mundo, y la Coordinadora Alemana para la Defensa de los Derechos Humanos en México que, como su nombre indica, es un conjunto de organizaciones que se dedica a defender a los afectados por la represión en México (Monterrubio, 2012; Atilano Uriarte, 2017).

De igual manera establecen contacto con diputados alemanes y funcionarios del Ministerio de Economía, específicamente con el doctor Werner Kautsch, a la sazón titular del Punto Nacional de Contacto, responsable de vigilar el cumplimiento de las directrices de la OCDE. Kautsch gestiona una reunión con el presidente del Consejo de Administración de Continental Tire, Manfred Wennemer, la cual se lleva a cabo con el apoyo en la traducción de Martin Wolpold de FIAN, pero no se llega a ningún acuerdo (Durán de Huerta, 2002; Monterrubio, 2012).

Al día siguiente consiguen participar en la Asamblea de Accionistas, por gestiones de la Federación de Accionistas Críticos de Alemania, ${ }^{3}$ que les otorga los salvoconductos para poder ingresar a la Asamblea y les asegura que, de

3. Un grupo de inversionistas progresistas "a favor de la protección del medio ambiente, la justicia social y la defensa de los derechos humanos, con sede en Colonia,Alemania" (Atilano Uriarte, 2017: 57), dedicado a la compra de acciones precisamente para poder protestar ante las políticas de las grandes empresas capitalistas. 
Avatares de a lucha obrera en la época neoliberal: la experiencia de la Sociedad Cooperativa Trabajadores Democráticos de Occidente

acuerdo con la Ley Alemana de Accionistas, el presidente de la compañía tiene la obligación de responder a los cuestionamientos que se le hagan. De este modo, ante más de mil accionistas reunidos en el Centro de Convenciones de Hannover, los representantes del SNRTE sostienen que el cierre de la planta de El Salto, Jalisco, es un acto ilegal y proponen dialogar para buscar una salida negociada al conflicto. Además, otros accionistas hacen referencia al irrefutable hecho de que para ese entonces Continental había "gastado 430 millones de euros en el cierre de cinco plantas desde septiembre pasado, por lo que Wennemer cuenta con el nada envidiable récord de una planta cerrada cada mes y medio" (Durán de Huerta, 2002). Al concluir la asamblea y ante la imposibilidad práctica de continuar eludiendo el conflicto que estaba dañando gravemente la imagen corporativa de la trasnacional, Wennemer sugiere trasladar las negociaciones a México, propuesta que la delegación sindical acepta (Cockcroft, Nájera y Torres, 2008).

Ya en México, después de infructuosas negociaciones con Jorge del Regil, abogado de Euzkadi en México, quien solamente ofrecía un pago de tres millones 900 mil pesos por concepto de terminación de contrato, equivalente a tres mil pesos por trabajador, el secretario general del SNRTE consigue reunirse con José da Silva Carballo Neto, gerente general de Continental México, quien le ofrece al sindicato 50 millones adicionales a las liquidaciones depositadas, que se repartirían entre todos los trabajadores, los que ya habían cobrado la liquidación y los que no. ${ }^{4}$ En asamblea general los trabajadores rechazan la oferta, y ratifican como demandas centrales del movimiento: el pago de salarios caídos y la reapertura incondicional e inmediata de la planta.

El 5 de julio de 2002 la jueza María Silvia Ortega del Juzgado Tercero de Distrito en Materia Laboral, ampara

4. Según Durán de Huerta (2002), hasta mediados de 2002, de los I, I 64 obreros iniciales sólo I0I habían cobrado su dinero. 
al sindicato frente a la resolución de la JFCA, al considerar que ésta no había cumplido con los procedimientos establecidos en la Ley (Durán de Huerta, 2002). La empresa intenta minimizar el significado político y jurídico de la resolución anterior, mediante una andanada de desplegados publicados en diversos periódicos locales de la ciudad de Guadalajara.

En mayo de 2003 se realiza una segunda visita a Alemania. Nuevamente los representantes sindicales consiguen ser escuchados por la asamblea de accionistas de Continental, pero durante el debate, Manfred Wennemer intenta justificar el cierre de la planta de El Salto, alegando que ésta "era totalmente improductiva y era necesario cerrarla para evitar mayores pérdidas" (Gómez, 2010: 110). En respuesta, Jesús Torres Nuño demuestra que la planta de Euzkadi era la más productiva y rentable del país y nuevamente propone buscar una solución negociada al conflicto. Al cierre de la asamblea, Manfred Wennemer se ve obligado a asumir el compromiso de retomar las negociaciones con el SNRTE.

Pero, a pesar del compromiso arriba indicado, las negociaciones no se reinician de forma inmediata, siendo hasta finales de agosto cuando la empresa y el sindicato se sientan a negociar. En las discusiones bilaterales, la compañía desacredita el proyecto de co-gestión propuesto por los trabajadores, manifiesta disposición a ceder el terreno y el edificio, pero hace todo lo posible por recuperar la maquinaria, el equipo y las cerca de 70,000 llantas almacenadas, llegando a ofrecer hasta 30 millones de pesos de liquidación para los poco más de 600 obreros que aún se mantenían en pie de lucha (Cockcroft, Nájera y Torres, 2008).

Así, no obstante la falta de acuerdos concretos, los obreros resisten y el 18 de febrero de 2004 logran que la JFCA declare la huelga legalmente existente. Inmediatamente la empresa promueve un amparo, que es desechado. 
Entre el 3 y el 23 de mayo de 2004, una nueva comitiva del SNRTE, a la cual se suman el diputado federal Pablo Franco y el abogado laboralista Alfonso Bouzas, es enviada a Europa. En esa ocasión los países visitados son Bélgica, Francia, Suiza y, por supuesto, Alemania. En Bélgica entran en contacto con dos grandes centrales sindicales con presencia mundial: la Confederación Internacional de Organizaciones Sindicales Libres (CIOSL) y la Confederación Europea de Sindicatos (CES). Asimismo, gracias a gestiones realizadas por las organizaciones sociales: German Watch y FIAN, y con la mediación de los eurodiputados: Alain Krivine y Roselyne Bachette, establecen una relación oficial con el Parlamento alemán que les permite introducir en la agenda del primer ministro la cuestión de la huelga (Monterrubio, 2012); incluso se llega a hablar de que el tema sería tratado como parte de los asuntos de interés de los respectivos mandatarios, Gerhard Schoroeder y Vicente Fox, durante la Cumbre entre la Unión Europea y América Latina y el Caribe, que estaba próxima a realizarse en Guadalajara.

Durante esa misma gira participan por tercera vez en la asamblea de accionistas de la Continental. Las intervenciones de Franco y Bouzas reciben una acogida entusiasta y claramente favorable entre los accionistas, de tal suerte que cuando toca el turno a Torres Nuño, éste se limita a emitir un discurso breve y a hacer entrega de una propuesta por escrito, que se resume en dos puntos: adquirir la planta por parte de los trabajadores e iniciar las negociaciones para el pago de salarios caídos. La Continental acepta estudiar la propuesta.

De regreso a México, nuevamente la Continental manifiesta una actitud cerrada y desdeñosa hacia el sindicato, actitud que, en cierta medida, era alentada por el gobierno de Vicente Fox, pues a mediados de 2004, cuando la huelga superaba los dos años, Carlos Abascal, en ese entonces secretario del Trabajo y Previsión Social, intentó convencer 
a los trabajadores de que aceptaran la liquidación que se les ofrecía con el argumento de que la fábrica, de acuerdo con estudios realizados por el Gobierno federal, ya no era viable. En realidad, como hemos visto, el conflicto tenía origen en el hecho de que las transnacionales llanteras buscaban destruir el Contrato Ley de la Industria Hulera como condición para mantener sus inversiones en México. Esta misma pretensión es la que explica el cierre ilegal de las plantas de Uniroyal en Tacuba y Querétaro, propiedad de la francesa Michelin, en agosto del año 2000, y de la planta de Tultitlán de Good Year Oxo, en marzo de 2001. En cambio, en Firestone, como explica Gómez (2010: 45), no fue necesario cerrar planta alguna debido a que la dirigencia sindical charra aceptó la firma de un nuevo contrato laboral que disponía: “[...] la reducción de personal, una jornada laboral de siete días de la semana, los obreros deberían ser multihabilidades y, lo más grave, una reducción del 25 por ciento en el salario".

Así pues, todas las acciones arbitrarias antes señaladas pudieron materializarse gracias a la colaboración de la CTM, que admitió el flagrante desconocimiento de los derechos laborales de los trabajadores, en las empresas unilateralmente cerradas. Pero cuando Continental lo pretendió hacer en Euzkadi, se encontró con una gran resistencia. Todo ello confirma que en realidad lo que se buscaba era destruir la organización sindical, que se oponía a los planes de reestructuración laboral y productiva de la transnacional. Por tanto, el problema no era que Euzkadi fuera económica o técnicamente inviable pues, como ya se indicó, llegó a ser considerada la planta llantera más moderna de América Latina, sino que se intentaba destruir la organización sindical, para posteriormente reabrir la planta, pero ya sin contrato colectivo y sin sindicato.

Así, contra viento y marea los trabajadores se mantuvieron firmes en sus demandas, logrando, el 17 de enero de 
Avatares de a lucha obrera en la época neoliberal: la experiencia de la Sociedad Cooperativa Trabajadores Democráticos de Occidente

2005, la firma de un Acuerdo Marco con la empresa, en una ceremonia realizada en la Secretaría del Trabajo, a la que asistió el entonces presidente Vicente Fox (Vargas, 2005). En éste el SNRTE acepta las liquidaciones, se compromete a retirar las demandas individuales de reinstalación y a levantar la huelga. La Continental, por su parte, se obliga a transferir a los trabajadores, en compensación por pasivos laborales, la mitad de la empresa (Cadena, 2005). La otra mitad sería adquirida por uno de sus clientes, la empresa de propiedad mexicana y sede en la ciudad de Querétaro, Llanti Systems; entregar 120 millones de pesos por liquidaciones pendientes de cobrar y retirar las demandas penales interpuestas contra algunos de los dirigentes sindicales.

Un hecho del cual vale la pena dejar constancia es que una vez que la transnacional se vio derrotada, el Gobierno federal, encabezado por Vicente Fox, cambió de postura e intentó aparecer como el factor decisivo que había permitido la solución de la huelga más larga e incómoda durante ese sexenio. Si bien el mismo Fox, el 11 de enero de 2005, firmó un decreto presidencial para facilitar la compra-venta de la planta, eximiendo del pago de impuestos por el traslado de dominio de la transnacional Continental a la cooperativa y aportó recursos frescos para rehabilitar la planta y capacitar a los trabajadores (Pastrana, 2005), en realidad la solución del conflicto obedecía fundamentalmente a la resistencia opuesta por los obreros y sus familias a lo largo de más tres años de huelga, el apoyo recibido de organizaciones nacionales e internacionales y la capacidad del sindicato para ofrecer una solución negociada.

Indudablemente, durante todo ese tiempo la empresa aplicó una estrategia tendente a vencer la resistencia obrera por hambre y cansancio. Por esta razón prolongó lo más posible los litigios laborales y, en paralelo, ofrecía a los obreros en lo individual, liquidaciones en efectivo y promesas de recontratación o asesoría para abrir changarros 
y autoemplearse. Aunado a lo anterior, los trabajadores de Euzkadi y sus familiares cercanos fueron incluidos en las "listas negras" de las empresas instaladas en el corredor industrial de El Salto, para que en ninguna de ellas les dieran trabajo. Dada esta circunstancia, el fortalecimiento de la solidaridad interfamiliar, tal como se documenta en la obra de María Atilano Uriarte: Mujeres: Sustento de la dignidad trabajadora en la huelga de Euzkadi, publicada en 2008, fue determinante.

De igual modo, las organizaciones sociales independientes, nacionales e internacionales, les brindaron importantes apoyos, entre los que se pueden mencionar los siguientes: la Sociedad Cooperativa Trabajadores de Pascual aportaba 6,000 pesos semanales y cada dos semanas 7,500 pesos adicionales. La Asociación Sindical de Pilotos Aviadores (ASPA) les proporcionó los boletos de avión durante la primera gira por Europa. El Sindicato Mexicano de Electricistas (SME) aportó 20,000 pesos para los gastos de la primera gira y el pago de un desplegado. La Coordinadora Intersindical Democrática Jalisciense hizo también una donación especial para la primera gira. Durante el tiempo que duró el conflicto, el Sindicato del Hospital Civil de Guadalajara les brindó atención médica irrestricta. El Fondo de Solidaridad de los Sindicatos Suizos Solifons les donó 10,000 euros que sirvieron para entregar una despensa a cada uno de los 650 trabajadores que se mantenían en lucha. La Fundación Heinrich Boll, de la Iglesia protestante alemana, durante los dos últimos años del movimiento pagó los boletos de avión y cubrió los gastos de las delegaciones del SNRTE durante la segunda y tercera giras europeas. Algunos diputados federales y locales les brindaron apoyo financiero y gestión, y promovieron puntos de acuerdo en apoyo al movimiento ${ }^{5}$ (Durán de Huerta, 2002; Monterrubio, 2012).

5. En contraste, el sindicato alemán de la Continental no solamente no los apoyó, sino que se opusieron a sus justas demandas.

\section{0}


Avatares de a lucha obrera en la época neoliberal: la experiencia de la Sociedad Cooperativa Trabajadores Democráticos de Occidente

Toda esta solidaridad rindió frutos y con base en el Acuerdo Marco, citado párrafos arriba, los obreros procedieron a la reapertura de la planta, pero ahora bajo control obrero. Se creaba así la que probablemente fuese la primera empresa que asociaba a una sociedad anónima con una cooperativa, la Corporación de Occidente, S. A. de C. V. (COOCSA), constituida el 5 de diciembre de 2004, mediante la fusión de Tradoc y Llanti Systems, con una participación accionaria equivalente al 50\% para cada una de las partes ${ }^{6}$ y un valor comercial, fijado por el Gobierno federal, en un monto global de 80 millones de dólares. Además, "Continental daría asesoría técnica para arrancar la planta y compraría 500 mil llantas al año [con lo que nunca cumplió]" (Luna Broda, 2010: 6). Finalmente, vale la pena apuntar que de los 971 trabajadores sindicalizados que había al momento del cierre de la planta, permanecieron hasta el final solamente 587 , es decir, el $60 \%$ de los trabajadores originales.

\section{El proceso de construcción de la cooperativa: 2005-2019}

Una vez ganada la lucha, el 5 de febrero de 2005 los trabajadores toman posesión formal de la planta e inician los trabajos de rehabilitación, pues después de tres años de huelga era necesario armar las máquinas que la empresa había desmontado en previsión de su probable traslado a otro lugar; además, se requería de una enorme cantidad de refacciones para rehabilitar la maquinaria y darle mantenimiento especializado. Junto con lo anterior, la limpieza general de naves de producción, de las oficinas y áreas verdes, formaron parte de las iniciales actividades desarrolladas por los cooperativistas.

6. La aportación al capital de la nueva empresa, por parte de los obreros, provino del pago que cada uno de ellos recibió por concepto de salarios caídos, por los I,I I I días que duró el paro laboral. 
Muy pronto la escasez de recursos y materia prima los obliga a buscar apoyo. Acuden al Gobierno federal y al estatal, consiguiendo del primero 45 millones de pesos y del segundo cinco millones adicionales que se destinaron para reparar la subestación eléctrica de la planta, que había sufrido una descompostura total. En ambos casos el crédito fue a fondo perdido. Además, por intermediación del entonces secretario del Trabajo y Previsión Social, Francisco Javier Salazar Sáenz, les conceden apoyos a través del Programa de Becas de Capacitación para el Trabajo (Probecat), lo que permitió que durante tres meses cada trabajador recibiera un total de 4,500 pesos mensuales. El monto total de este apoyo fue de alrededor de 10 millones de pesos.

Así las cosas, no será sino hasta el 9 julio de 2005 cuando se reanude la producción de llantas que, a partir de ese momento, dejaron de llevar impresa la palabra Euzkadi. En ese momento su capacidad productiva, a decir de Enrique Gómez, se ubicaba escasamente en cien llantas por día.

Durante los primeros años de vida la cooperativa tuvo pérdidas pues padecía una constante falta de materia prima (hule natural y negro de humo, principalmente), de tal modo que no lograba superar el límite de cinco mil llantas diarias de producción, que no cubrían los costos de operación. La situación anterior se complicó en 2008, dadas las graves consecuencias de la crisis económica mundial que estalló ese año, por lo que ante la necesidad de abastecerse de suficiente materia prima, la cooperativa resuelve buscar un socio más.

Tras una larga búsqueda y arduas negociaciones, en la segunda mitad de 2008 la compañía Cooper Tires \& Ruber Company, con oficinas centrales en Findlay, Ohio, Estados Unidos, ${ }^{7}$ fue invitada a formar una empresa de co-inver-

7. Cooper Tires \& Rubber Company es una compañía global, con presencia en $6 \mathrm{I}$ países, que se especializa en el diseño, fabricación, comercialización y venta de

\section{2}


Avatares de a lucha obrera en la época neoliberal: la experiencia de la Sociedad Cooperativa Trabajadores Democráticos de Occidente

sión con Coocsa. La distribución accionaria de la nueva empresa se dividió de la siguiente manera: la cooperativa Tradoc se quedó con el 42\%, Cooper Tires recibió el 16\% y Llanti Systems retuvo el restante 42\%. Este convenio le proporcionó a COOCSA el acceso a materias primas a precios competitivos, además de tecnología, moldes, maquinaria y asistencia técnica; vinculación a una importante red de marketing internacional, y la inyección de más de 14 millones de dólares en capital, que aumentaron sustancialmente el valor de la empresa. De este modo, a pesar de la reducción al $42 \%$ en la tenencia de las acciones totales, los socios de la cooperativa se vieron compensados por el aumento en el valor global de la empresa. Finalmente, de acuerdo con el convenio suscrito por las partes, la nueva compañía: Cooper Tires \& Ruber Company de México, S. A. de C. V., se haría cargo de la comercialización, venta y distribución de las marcas de Cooper; Llanti Systems seguiría con la distribución de las propias, y Tradoc, por su parte, se dedicaría a la producción en serie de los neumáticos.

Unos meses después, Llanti Systems, al vender sus acciones a Cooper, abandonó la sociedad. En el acuerdo de salida, junto a la cesión de la marca Blackstone, ya registrada, a favor de la cooperativa, se fijó un porcentaje de $5 \%$ de la producción para esa marca, lo que permitió a Tradoc establecer su propia comercializadora, denominada: Blackstone Tires, cuya distribución sería realizada a través de canales propios.

Gracias a esta segunda fusión y al incremento de un 100\% en la capacidad productiva de la planta, el ejercicio fiscal 2009 fue el primero en que el corporativo obtuvo dividendos. De éstos, a Tradoc le correspondieron 20 millones de pesos que, en asamblea general, los socios decidieron distribuir de la siguiente manera: nueve millones para reinversión, seis

neumáticos para automóviles de pasajeros, camiones ligeros y medianos, así como en llantas para motocicletas y autos de carreras.

Sociedad No.82 
millones para la capitalización de Tradoc y cinco millones para repartir entre los cooperativistas, de acuerdo con el monto que amparara cada uno de los certificados de aportación (Monterrubio, 2012). Cabe destacar que la inversión realizada tuvo como objetivo modernizar la planta, adquiriendo equipo para fabricar solamente llantas radiales, consideradas las más modernas en el mercado, y eliminar la producción de llantas convencionales.

Ahora bien, en lo que se refiere a los procesos de toma de decisiones, hasta el 1 de noviembre de 2019 la corporación operó mediante un consejo de administración bipartito compuesto por siete miembros, de quienes Tradoc designaba a tres. Sin embargo, en la mayoría de los casos las decisiones se adoptaron por consenso.

En cuanto a la contratación de personal, después de 2008 Tradoc constituyó una cooperativa de trabajo, denominada Producción Empresarial Profesional, S. C. de R. L. de C. V. (Proem), con la finalidad de incluir a los nuevos trabajadores que se fuesen incorporando y evitar así la injerencia de sindicatos, como la ya mencionada Стм, que pudiesen ofrecer contratos de protección patronal sin el debido conocimiento y aceptación de los trabajadores. Por esta misma razón, únicamente los socios de Tradoc podrían integrar el consejo de administración encargado de dirigir la planta, en tanto que los nuevos trabajadores sólo podían llegar a ser socios de Tradoc después de cumplir un periodo de prueba de cinco años en la cooperativa Proem y suscribir un certificado de aportación obligatoria de 50,000 pesos. A nivel del corporativo, el acuerdo que prevaleció con las empresas privadas aliadas, fue que éstas no debían intervenir en las relaciones de trabajo, "sino sólo en el rubro de comercialización, planeamiento y adquisición de materia prima” (Luna Broda, 2010: 7).

Bajo este esquema, a mediados de 2019 daba empleo a 580 personas, quienes percibían un ingreso promedio mensual 
Avatares de a lucha obrera en la época neoliberal: la experiencia de la Sociedad Cooperativa Trabajadores Democráticos de Occidente

de 17,945 pesos, tarifa a la cual también estaban sujetos los directivos. Los jefes de producción ganaban 25,000 pesos mensuales y, en su conjunto, la nómina semanal ascendía a 3.5 millones de pesos, de los cuales el 70\% se derramaba en El Salto y Juanacatlán, y el 30\% restante en los municipios de la zona metropolitana de Guadalajara.

Con tales indicadores, la cooperativa era una de las empresas sociales más destacadas del país y una de las cinco más importantes del estado de Jalisco. Los socios-trabajadores de Tradoc gozaban de los mayores ingresos y de las mejores condiciones laborales en todo Jalisco. Los siguientes datos, proporcionados por los trabajadores de base entrevistados, corroboran lo anterior: Sus percepciones se componían de un adelanto a rendimiento base, bono de productividad que representaba el $40 \%$ del estipendio; bono de asistencia, equivalente al pago de una semana de su adelanto a rendimiento sin una falta cada tres meses y, si en todo el año el trabajador registraba cero inasistencias, obtenía cinco semanas de adelanto a rendimiento en total. La semana laboral era de 40 horas; pero, en caso de laborar el sábado, ese día se pagaba como tiempo extra. Tenían derecho a transporte gratuito y ayuda para gastos funerarios, por un monto de 20,000 pesos, que aplicaba a cualquier familiar directo del socio y si se trataba de éste, se le cubrían todos los gastos. Recibían 35 días de aguinaldo adicionales a los excedentes anuales que la cooperativa les distribuía al final del ejercicio fiscal. A lo socios pensionados ${ }^{8}$ la cooperativa les pagaba puntualmente sus certificados de aportación, más un 30\% de su valor, además de una digna pensión que se ubicaba por encima de los 25 mil pesos mensuales.

A lo anterior habría que añadir cuatro elementos de crucial importancia que ponen de manifiesto la calidad de las condiciones de trabajo, así como el ambiente laboral

8. En Tradoc, los socios-trabajadores se pensionaban a los 60 años de edad. A mediados de 2019 el número de éstos ascendía a poco más de 300 .

Sociedad No.82 
que se había logrado construir. Dichos elementos son: en primer lugar, el hecho de que los socios de reciente ingreso gozaban de las mismas percepciones y prestaciones que el resto de los socios fundadores. En segundo lugar, que las percepciones estaban ligadas al trabajo desempeñado por cada quien, de tal modo que éstas se fijaban de acuerdo con la regla de "a igual trabajo, igual percepción". En tercer lugar, que el trabajo en las naves de producción, antes reservadas exclusivamente a los varones, se habían abierto para la participación de las mujeres, quienes laboraban en igualdad de condiciones que los hombres y gozaban de las mismas percepciones y derechos. Y, finalmente, que todo este ambiente laboral se mantenía y reproducía en condiciones de autogestión colectiva, es decir, sin necesidad de supervisores o capataces, apelando exclusivamente a la conciencia y compromiso personal de cada trabajador.

Un último aspecto a destacar en la acción colectiva de la cooperativa Tradoc, ha sido su permanente solidaridad con otras luchas obreras y populares. Un caso emblemático de ello, destacado enfáticamente por Jesús Torres Nuño durante la entrevista, fue el apoyo otorgado a Industrias Ocotlán, una empresa jalisciense que protagonizó una huelga prolongada en el año 2015 y a raíz de la cual la cooperativa ofreció empleo provisional — sin distinción de edad, ni requisito alguno- a más de 150 trabajadores en su planta, amén de acompañarlos en los actos de presión contra sus patrones realizados en la Ciudad de México. De igual modo, han apoyado reiteradamente a los trabajadores del sme y a los pobladores de Atenco, Estado de México, así como a muchos otros grupos que han tocado sus puertas, entre los que se cuentan los indígenas del EZLN y los normalistas de Ayotzinapa, Guerrero. 
Avatares de a lucha obrera en la época neoliberal: la experiencia de la Sociedad Cooperativa Trabajadores Democráticos de Occidente

\section{La difícil situación actual y sus retos}

En contraste con los logros enumerados en el apartado anterior, la cooperativa se ha visto afectada por un conjunto de problemas que han aparecido de manera recurrente a lo largo de su historia. El primero de ellos tiene que ver con diversos conflictos internos entre distintos grupos o corrientes de opinión, motivados, en parte, por las dificultades implícitas en el complejo proceso de transición, aún no completado, desde una identidad colectiva sindicalista hacia otra de carácter cooperativista, lo que entraña un cambio drástico entre el rol que desempeña un obrero industrial subordinado a un patrón y el que se espera de un trabajador que, a su vez, es dueño de la empresa en la que labora. Algunos de estos conflictos no han conseguido resolverse por una vía conciliatoria en los órganos internos de participación y decisión, y han trascendido al ámbito jurídico mediante la presentación de diversas demandas legales ante distintas instancias judiciales, en las que se reclaman indemnizaciones millonarias a favor de los quejosos. Afortunadamente, hasta el día de hoy ninguna de estas iniciativas legales ha prosperado.

Pero, sin duda, los dos mayores retos que ha enfrentado desde su formación son los relacionados con la agresiva competencia de las trasnacionales del ramo y el acelerado proceso de modernización tecnológica que se ha producido en los últimos años. La magnitud del primero de ellos es enorme, pues la disputa por los mercados la realiza con las seis transnacionales que producen en el país; tales 
empresas son: Michelin, ${ }^{9}$ Continental,,${ }^{10}$ Bridgestone, ${ }^{11} \mathrm{JK}$ Tire, ${ }^{12}$ Pirelli ${ }^{13}$ y Goodyear. ${ }^{14}$ Además, la mayoría de estas empresas funcionan bajo contratos de protección patronal, lo que se traduce en una competencia desleal.

A lo anterior habría que sumarle el hecho de que la asamblea general de la cooperativa nunca aceptó la formación del fondo de reserva establecido en la Ley General de Sociedades Cooperativas vigente, medida que fue reiteradamente propuesta por el consejo de administración. Esta circunstancia impidió hacer más inversiones en el desarrollo

9. Michelin se estableció en la ciudad de Querétaro en 1989 y emplea más de 700 personas. Comercializa productos para los mercados de automóviles, mueve-tierra, equipo agrícola y camiones pesados. En los últimos años ha realizado inversiones superiores a los 500 millones de dólares que le permiten producir llantas con rines de más de 17 pulgadas. Su sede principal se ubica en Greenville, Carolina del Sur, Estados Unidos.

10. Continental Tire de México es filial del Grupo Continental, empresa alemana dedicada al diseño, manufactura, comercialización y distribución de llantas de equipo original y productos de hule. En noviembre de 2017 abrió una planta industrial en la ciudad de San Luis Potosí, en donde produce llantas para automóvil y camioneta de las marcas Continental, Euzkadi y General Tire. Tiene además la mayor red de distribución en el país, con más de 500 puntos de venta. Emplea a cerca de 10,000 personas, ya sea en sus oficinas administrativas de la Ciudad de México, la planta industrial o los centros de distribución.

II. Bridgestone Firestone de México es una filial de BridgestoneAmerican Holding, Inc. que, a su vez, es subsidiaria de Bridgestone Corporation de Japón, el fabricante de neumáticos y productos de hule más grande del mundo. Bridgestone de México cuenta con dos plantas en Cuernavaca, Morelos, y en Monterrey, Nuevo León.

12. JK Tire, cuya matriz se asienta en Delhi, India, entró al país en 2008, año en el que adquirió todos los activos de la antigua empresa mexicana Tornel.Actualmente cuenta con cuatro plantas, tres en el Distrito Federal y una en el Estado de México. 13. Pirelli es una empresa de capital italiano que en marzo de 201 I estableció la planta industrial número 22 de la firma en Silao, Guanajuato. Dicha planta está considerada como uno de los complejos industriales más modernos de América Latina con capacidad para producir llantas con rines superiores a las 17 pulgadas. Actualmente exporta a 40 países del mundo, principalmente a Estados Unidos y Canadá.

14. Con una inversión superior a 550 millones de dólares, la multinacional Goodyear abrió en 2017 una moderna planta industrial en San Luis Potosí asentada sobre una superficie de 405 mil metros cuadrados, que la convierten en la más grande en su tipo en América Latina.Tiene, además, capacidad para producir más de seis millones de neumáticos al año con rines de entre 18 y 24 pulgadas, genera I,000 empleos directos y 5,000 indirectos, y coloca una parte considerable de su producción en diversos países de América Latina y en Estados Unidos. 
de la marca Blackstone, lo que frenaba su desarrollo, pues con relativa frecuencia se requerían moldes, apertura de tiendas, publicidad, etc., aspectos indispensables en aras de lograr una mayor penetración en el mercado.

Otro aspecto de suma gravedad, derivado de la falta de regulación de la competencia económica en el sector productor de llantas, está relacionado con la invasión, muchas veces ilegal, de llantas de origen chino. Este problema se agravó a raíz de la publicación en el Diario Oficial de la Federación el 16 de diciembre de 2009, de un decreto por el que se redujo de 35 a $30 \%$ el arancel a la importación de llantas para camión, beneficiando a los productores asiáticos, quienes además tienen costos de mano de obra bajísimos y gozan de subsidios gubernamentales. Por esta razón la producción de llantas para camión resulta totalmente prohibitiva para una empresa social como Tradoc, que labora en medio de la amenaza constante de que se aplique una reducción generalizada a la importación de todo tipo de llantas.

Un último dato que vale la pena registrar es que la materia prima con la que trabajan no se elabora en el país, ello a pesar de que la región sureste del país tiene un enorme potencial, aún sin desarrollar, por lo que su capacidad productiva actual no alcanza a satisfacer la demanda de la planta de El Salto. En el pasado reciente Tradoc realizó un esfuerzo denodado por comprarles a los productores nacionales; pero, a la postre, éste resulto infructuoso. Así que la materia prima la importan de Guatemala, Indonesia y Malasia. Las sustancias y elementos químicos provienen de Europa y Estados Unidos.

A pesar de este panorama adverso, en 2014, de acuerdo con Elizabeth Rivera (2014), la planta de la cooperativa produjo 4.3 millones de neumáticos y facturó ventas por 300 millones de dólares. En 2019 alcanzó la cifra de 18 mil llantas diarias 
de tipo radial. De éstas, el 60\% las exportó a Estados Unidos y el restante $40 \%$ se colocó en el mercado nacional.

En cuanto al segundo reto, vinculado al desarrollo tecnológico, es imperativo reconocer que, aunque la planta de El Salto ha realizado importantes esfuerzos de modernización, instalando maquinaria automatizada, tecnología de punta y personal altamente capacitado, no le ha alcanzado para ponerse a la altura de los avances tecnológicos incorporados a la industria automotriz en los últimos años, lo cual ha provocado que la producción de llantas se haya transformado radicalmente en un periodo relativamente corto. Entre otras cosas, este fenómeno se ha expresado mediante la introducción de neumáticos de mayor tamaño con rines de 18 a 24 pulgadas, que la planta de la cooperativa no produce. Tales modelos han sido impuestos por las trasnacionales que controlan la industria automotriz y están ocupando con ellos cada vez más amplias franjas del mercado. Responder con eficacia a este colosal reto implicaría llevar a cabo una reconversión tecnológica de gran magnitud, misma que demandaría una inversión superior a los 200 millones de dólares, que irremediablemente han quedado fuera del alcance de la cooperativa.

$\mathrm{Y}$ es precisamente este último reto, que devino un obstáculo insalvable, el que explica la difícil decisión tomada por los cooperativistas de Tradoc el 1 de noviembre de 2019, cuando reunidos en asamblea general extraordinaria acordaron la venta del 100\% de las acciones que mantenían en COocsa a su socio global Cooper Tire. ${ }^{15}$ De hecho, desde el año 2016 Cooper venía ejerciendo una presión muy fuerte sobre el consejo de administración de la cooperativa para que se realizaran cuantiosas inversiones que les permitieran mantenerse al día en la competencia con otras empresas.

15. El acuerdo consignado en el acta respectiva se adoptó con 387 votos a favor, I 46 en contra y dos abstenciones. Lo que representa el $66.37 \%$ de los socios de la cooperativa. 
Avatares de a lucha obrera en la época neoliberal: la experiencia de la Sociedad Cooperativa Trabajadores Democráticos de Occidente

Tales presiones colocaban a Tradoc ante una disyuntiva: realizar las inversiones que se requerían o mantener el empleo de todos los trabajadores con los niveles salariales y las prestaciones laborales antes indicadas. Cumplir con ambas exigencias era prácticamente imposible, así que la cooperativa se inclinó por proteger los derechos de los trabajadores.

En este contexto, desde finales de 2018, según se puede leer en el Manifiesto que el consejo de administración de Tradoc dio a conocer públicamente el pasado 3 de noviembre de $2019,{ }^{16}$ Cooper ya no sólo insistió en modernizar la planta, sino que manifestó su interés por ejercer el control total de la empresa, ofreciendo a cambio comprar las acciones de Tradoc. Para cumplir con tales propósitos, Cooper realizaría un avalúo de la empresa y presentaría una propuesta integral en la que, además del monto de la oferta económica, se especificarían las condiciones sociales y laborales en las que quedarían los socios de la cooperativa tras la compra de las acciones.

El avalúo fue presentado en junio de 2019 y entre julio y octubre se negociaron las siguientes condiciones sociales y laborales para los trabajadores: 1) todos los socios de Tradoc y Proem, además de recibir su liquidación constitucional, serán recontratados; 2) las relaciones laborales continuarán regidas por el Contrato Ley de la Industria Hulera; 3) se formará un nuevo sindicato independiente y democrático que emulará la experiencia del SNRTE; 4) la cooperativa Tradoc no desaparece sino que se mantiene, ocupando el $5 \%$ de la producción total de la planta para la marca Blackstone, cuya distribución se continuará realizando a través de la Comercializadora Blackstone Tires; 5) Cooper garantiza asesoría técnica para modernizar los moldes de la marca de la cooperativa y aportará 100 mil dólares anuales durante

16. Un resumen del mismo puede consultarse en la plataforma digital: https:// lacoperacha.org.mx

Sociedad No.82 
los primeros tres años, que se destinarán a dicho fin; 6) con el $15 \%$ de la cantidad pagada por las acciones, se crearán reservas económicas para enfrentar cualquier contingencia legal, ya sea de parte de instancias gubernamentales o de ex trabajadores, y 7) Tradoc realizará reuniones trimestrales con la administración de la empresa para recibir información financiera y revisar cualquier problema de orden técnico-productivo.

Teniendo como telón de fondo los hechos anteriormente comentados, el 19 de diciembre de 2019 la asamblea general del Tradoc, al renovar sus cuerpos directivos, con una diferencia de apenas 21 votos le dio la victoria a un grupo opositor a la corriente histórica que venía encabezando la cooperativa desde 2005. De esta forma, dado el desgaste natural sufrido durante los 15 años que permaneció al frente de la cooperativa y habiendo cumplido un ciclo completo en funciones de dirección, la emblemática figura de Jesús Torres Nuño fue sustituida por la menos conocida de César Mavael Rodríguez en la presidencia del consejo de administración.

Un último dato que vale la pena consignar es que en los primeros meses de 2020 se consiguió el registro del nuevo Sindicato Nacional de Trabajadores Democráticos de Occidente (Sntradoc), así como la adhesión de coocsa al Contrato Ley de la Industria Hulera, lo que garantiza que ese innovador Contrato Ley sea el que continúe rigiendo las relaciones laborales.

\section{Conclusiones generales}

Como hemos visto, entre los factores que posibilitaron el triunfo de la lucha obrera ante la transnacional Continental, destacan básicamente tres. En primer lugar, la amplia política de alianzas establecida más allá del sindicalismo oficial, con diversas organizaciones y movimientos socia- 
Avatares de a lucha obrera en la época neoliberal: la experiencia de la Sociedad Cooperativa Trabajadores Democráticos de Occidente

les independientes. En segundo lugar, el ejercicio de la solidaridad interfamiliar y popular en todas sus formas y, en tercer lugar, el internacionalismo desplegado. Con este último elemento lo que se intentaba era desenmascarar a la Continental en su propia tierra. Ello implicó desarrollar una estrategia de denuncia durante tres años en las asambleas de accionistas, a la par que se realizaba una amplia labor de difusión tendente a conseguir simpatías y apoyos diversos de parte de organizaciones sociales progresistas en Alemania y otros países europeos, hasta obtener una salida negociada al conflicto.

Vinieron después los difíciles años de la conversión de los obreros en cooperativistas, mediante largas y penosas jornadas de capacitación organizacional y de educación cooperativa, así como la ardua labor de reemprender la actividad productiva, enfrentar la dura competencia comercial y tener que asumir la espinosa decisión de establecer alianzas de negocios con otras empresas privadas transnacionales, sin afectar los intereses de los socios-trabajadores.

Y a mediados de 2020, cualquier crítico mal intencionado podría decir que la lucha de los trabajadores de Euzkadi resultó infecunda porque al cabo de 15 años de bregar por la defensa de sus intereses legítimos, se encuentran en el mismo punto de partida, es decir, reconvertidos en obreros subordinados a un patrón. Pero realmente no es así. Antes de 2001 sólo eran trabajadores, dueños de su fuerza de trabajo. Ahora poseen una cooperativa con activos importantes y, aunque ciertamente vuelven a ser obreros, lo hacen bajo la protección de un sindicato democrático y bajo el amparo de un contrato colectivo. Lo cual no es poco si se toma en cuenta que la tendencia dominante en la industria automotriz indica que en los próximos años la reconversión tecnológica continuará a escala mundial, lo que provocará una fuerte concentración del capital con fusiones empresariales alrededor de los consorcios que lideren los procesos 
de adopción de las innovaciones tecnológicas. A los trabajadores, en cambio, como han señalado Gómez y Pacheco (2014), les aguarda un futuro poco alentador, condicionado por un aumento descomunal del desempleo que presionará para que la precarización del trabajo de los obreros en activo sea aún mayor.

Asimismo es fundamental preguntarnos por qué suceden este tipo de cosas: ¿por qué las luchas de los trabajadores encaminadas hacia la autogestión empresarial, a menudo tienden a fracasar? ¿Por qué el Estado en lugar de asumir un rol facilitador de acuerdos obrero-patronales mutuamente beneficiosos para las partes en disputa, parece situarse indefectiblemente del lado patronal? ¿Será acaso cierto que la dominación del capital es imbatible? En realidad, en México la dificultad principal es de orden macroeconómico, político y jurídico. Por esta razón coincidimos con José González (2005) y Martha Izquierdo (2009), quienes han subrayado las adversas condiciones en las que las cooperativas desenvuelven sus actividades sociales y empresariales. Así pues, los trabajadores no sólo luchan contra los patrones sino contra los gobiernos en turno, contra un marco jurídico desfavorable y contra el sesgo antisocial de las políticas públicas. Frente a tal cúmulo de adversidades, únicamente la unidad y la solidaridad del movimiento cooperativo y de otros movimientos sociales progresistas pueden augurar un mejor futuro para las luchas sindicales en pro de la autogestión empresarial. De hecho, la sobrevivencia de Tradoc durante los próximos años dependerá, en buena medida, de que consiga colocar su producto en el mercado. El consumo responsable y solidario de los cerca de nueve millones de cooperativistas y de las más de 60,000 empresas sociales que existen en el país, podría ser una alternativa viable.

De igual modo tendrán que resolver el difícil trance que significa manejar, de manera simultánea y con transparencia y democracia efectiva, dos instancias de participación y 
Avatares de a lucha obrera en la época neoliberal: la experiencia de la Sociedad Cooperativa Trabajadores Democráticos de Occidente

de gestión totalmente diferentes, como lo son: un sindicato y una cooperativa. Si en lugar de competir o de confrontarse entre sí, cooperan y se complementan mutuamente, es posible augurar que las relaciones internas se fortalecerán y se podrá dar un salto de calidad en la conciencia obrera. En caso contrario, el escenario puede enturbiarse rápidamente y convertirse en controversias y enfrentamientos infructuosos que únicamente beneficiarán a la empresa capitalista con la que irremediablemente se mantienen ligados.

Un último punto nodal es el inevitable cambio generacional que habrá de producirse en los próximos años, de tal suerte que si se desea que éste sea positivo, tendrá que trabajarse arduamente con los trabajadores más jóvenes a fin de que conozcan y valoren el origen de Tradoc y asuman las características que le han dado sustento a lo largo de su historia, dando paso así a un liderazgo renovado y visionario capaz de darle continuidad al proyecto autogestivo y libertario de la cooperativa.

A manera de cierre, podemos concluir señalando que Tradoc es un ejemplo vivo que demuestra que la clase trabajadora es capaz no sólo de enfrentar a una poderosa transnacional apoyada por el Gobierno, sino también de administrar exitosamente una gran empresa de talla internacional. Que es capaz de adaptarse a las más variantes condiciones políticas y laborales como las que supone pasar de una organización sindical a otra cooperativa, y finalmente a manejar ambos espacios de participación social sin perder de vista que lo determinante, en última instancia, es lograr la apropiación directa del valor generado en el proceso productivo, puesto que sólo de esa manera es posible alterar los mecanismos que sustentan la dominación del capital sobre el trabajo. La experiencia de Tradoc evidencia, en suma, que la organización cooperativa es una de las formas más apropiadas para propiciar la autoemancipación de los 
trabajadores en la perspectiva delineada por el paradigma de la economía social y solidaria.

Bibliografía

Atilano Uriarte, M. (2008). Mujeres: Sustento de la dignidad trabajadora en la huelga de Euzkadi. México: Henrich Boll Stiftung.

- (2017). Tradoc: La esperanza obrera. México: Ediciones de la Rosa Luxemburg Stiftung.

Barajas, J., De Buen, N., Dorantes, Á., y Gómez, E. (2002). Euzkadi. Crónica y parte de guerra. México: La Casa del Mago.

Cadena, G. (2005, I 8 de enero). Fin a tres años de conflicto laboral en Euzkadi. El Financiero, p. 17. Recuperado de: http://impreso.elfinanciero.com.mx/pages/Ejemplar.aspx Cámara de Diputados del H. Congreso de la Unión. (2009). Decreto por el que se modifica la Tarifa de la Ley de los Impuestos Generales de Importación y de Exportación. Diario Oficial de la Federación. Recuperado de: http:// www.dof.gob.mx/nota_to_imagen_fs.php? Código nota: 5/249/6. Fecha: I6/12/2009.

_. (2019). Ley Federal del Trabajo. Diario Oficial de la Federación, última reforma publicada 2-07-2019. Recuperado de: http://www.camaradediputados.gob.mx

Crockcroft, J. D., Nájera, M. A., y Torres Nuño, J. (2008). Testimonio de una victoria obrera del siglo XXI. Una huelga internacionalista ejemplar: La batalla de Euzkadi. Guadalajara: Ediciones Presente y Futuro.

Durán de Huerta, M. (2002, 21 de julio). Bitácora de viaje a las entrañas de una transnacional. La Jornada, Masiosare, núm. 239. Recuperado de: https://www.jornada.com. $\mathrm{mx} / 2002 / 07 / 21 /$ mas-cara.html

Gómez Delgado, E. (2005). Ellos sí pudieron mirar el cielo: La victoria obrera en Euzkadi.México:Ediciones El Socialista. 
- (2019,9 de diciembre). Entrevista personal en su calidad de asesor de la Cooperativa Tradoc [J.J. Rojas, entrevistador]. Ciudad de México, México.

Gómez Solórzano, M.A.,y Pacheco Reyes, C. (20I4). Trabajo informal, economía solidaria y autogestión. Precariedad laboral y resistencia en la globalización. Buenos Aires: Peña Lillo/Ediciones Continente.

González Méndez,J. (2005, I 8 de julio). Con todo en contra. La Jornada. Recuperado de: http://www.jornada.unam. $\mathrm{mx} / 2005 / 08 / 0 \mathrm{l} / 006 \mathrm{nlsec}$.html

Instituto de Información Estadística y Geográfica de Jalisco. (2019a). El Salto. Diagnóstico municipal. Recuperado de: https://iieg.gob.mx/ns/wp-content/uploads/2019/06/ El-Salto.pdf

—. (20|9b).Juanacatlán. Diagnóstico municipal. Recuperado de:https://iieg.gob.mx/ns/wp-content/uploads/2019/06/ Juanacatlan.pdf

Izquierdo Muciño, M.E.(20I9). Problemas en las cooperativas mexicanas que atentan contra el principio de autonomía e independencia. Boletín de la Asociación Internacional de Derecho Cooperativo, núm. 55, pp. 35-54. doi:http://dx.doi. org/10.18543/baide-55-2019pp35-54.

Jara Holliday, O. (2018). La sistematización de experiencias:Práctica y teoría para otros mundos posibles. Bogotá: Centro Internacional de Educación y Desarrollo Humano.

Luna Broda, S. (2010). Apuntes para la discusión sobre la autogestión obrera y la precarización laboral en empresas transnacionales a partir del caso de Euzkadi en México. Osera, núm. 4, pp. I-I6.

Maldonado Leal, E.(I98I). Breve historia del movimiento obrero. Culiacán: Universidad Autónoma de Sinaloa.

Martínez González, P., y Hernández, E. (2009). Impactos de la contaminación del Río Santiago en el bienestar de los habitantes de El Salto, Jalisco. Espacio Abierto, I8(4): 709-729. 
Bibliografía

Miranda Bello, P. A. (2016). Control obrero y democracia en el proceso de trabajo: El caso de Trabajadores Democráticos de Occidente. Tesis de maestría inédita. México, DF: UAM-Iztapalapa.

Monterrubio Alfaro, G. (20/2). Rodando por la autopista del capitalismo en crisis. Revista Nómada. Recuperado de: http://libertadyconcordia.wordpress.com/2012/05/07/ rodando-por-la-autopista-del-capitalismo-en-crisis-tradocl

Pastrana, D. (2005, 25 de enero). México: Euzkadi, el triunfo de la resistencia obrera. La Jornada, Masiosare, núm. 370. Recuperado de: https://www.jornada.com. $\mathrm{mx} / 2002 / 0 \mathrm{l} / 23 / \mathrm{mas}$-cara.html

Quintero,A.G.(20I4). El legado sindical en las cooperativas: $L a$ experiencia de los ex trabajadores de Euzkadi y la dinámica en Tradoc. Tesis de maestría inédita. México, DF: FLACSO.

Rivera Avelar, E. (20I4, 5 de diciembre). La Sociedad Cooperativa Trabajadores de Occidente (Tradoc) cumplió diez años. La Jornada Jalisco. Recuperado de: http://crónicassociales.org/20 I4/I2/05/tradoc-cumplio-diez-anos/

Ruiz Ortiz, C. (1997). Sesenta años del sindicato de Euzkadi. México: Ediciones SNRTE.

Torres Nuño, J. (2019,2I de octubre). Entrevista personal en su calidad de presidente del Consejo de Administración de la CooperativaTradoc [J.J. Rojas, entrevistador]. Guadalajara, Jalisco, México.

Vargas, R. E. (2005, I8 de enero). Trabajadores de Euzkadi celebran frente a Fox el triunfo ante la empresa alemana. La Jornada, p. I 3. Recuperado de: https://www.jornada. com.mx/2005/0I/I8/0 I3n I pol.php 